\title{
A Novel Liquid-Liquid Microextraction Based on Solidification of Floating Organic Droplet Method for Determination of Phenols in Aqueous Samples
}

\author{
H. Faraji ${ }^{1, *}$, M. Mirzaee ${ }^{2}$, F. Sorkheh ${ }^{2}$, M. Helalizadeh ${ }^{2}$ and A.A. Tabrizi ${ }^{2}$ \\ ${ }^{I}$ Department of Chemistry, Islamic Azad University Varamin branch, Varamin, Iran \\ ${ }^{2}$ Young researchers club, Islamic Azad University Varamin branch, Varamin, Iran
}

\begin{abstract}
Pre-concentration and determination of 7 phenolic compounds in water samples has been achieved using a new liquid-liquid microextraction coupled HPLC-DAD. Microextraction efficiency factors have been investigated and optimized: $14 \mu \mathrm{L}$ 1-undecanol micro drop exposed for 15 min floated on surface of a $20 \mathrm{~mL}$ water sample at $55^{\circ} \mathrm{C}$, stirred at $1200 \mathrm{rpm}$, low $\mathrm{pH}$ level and saturated salt conditions. Under the selected conditions, limit of detection of $0.5-3.0 \mu \mathrm{g} \mathrm{L}^{-1}$ $(\mathrm{S} / \mathrm{N}=3)$ and linearity range of $0.3-870 \mu \mathrm{g} \mathrm{L}^{-1}$ have been obtained. A reasonable repeatability $(\mathrm{RSD} \leq 10.1 \%, \mathrm{n}=5)$ with satisfactory linearity $\left(0.9992 \geq r^{2} \geq 0.9973\right)$ of results illustrated a good performance of the present method. The relative recovery of different natural water samples was higher than $84 \%$.
\end{abstract}

Keywords: Phenols, LPME, Water sample, HPLC-DAD.

\section{INTRODUCTION}

Phenolic compounds are important water pollutions which are subject to legislation because of their toxicity, even at low concentration. A European Community (EC) directive specifies a legal tolerance level of $0.1 \mu \mathrm{g} \mathrm{L}^{-1}$ for each phenolic compounds and $0.5 \mu \mathrm{g} \mathrm{L}^{-1}$ for the sum of all compounds in water intended for human consumption [1,2]. Phenols are usually determined by many analytical approaches such as high-performance liquid chromatography (HPLC) [3-5], capillary gas chromatography (GC) [6], spectrophotometery [7] and electrochemical methods [8]. GC has been widely used for the analysis of phenols, usually with a derivatization step $[9,10]$. However, derivatization increases the sample preparation time and introduces a possible source of errors.

Despite technological advances in instrumentation of chemical analysis, the resultant sensitivities are limited. Anyway the determination of phenolic compounds usually requires sample pre-concentration through liquid-liquid extraction (LLE) [11] or solid-phase extraction (SPE) $[12,13]$. These methods are time-consuming and are required large amounts of solvents. Solid phase microextraction (SPME) $[14,15]$, headspace solid-phase microextraction (HSPME) [16] and stir bar sorptive extraction (SBSE) $[17,18]$ are solvent-free and fast, however, they are expensive and their sorbents are fragile. Further, they have limited lifetime and also sample carry-over can be a problem. Jeannot and Cantwell developed liquid-liquid microextraction (LLME) system in which extraction was achieved into a single drop

*Address correspondence to this author at the No 14, Mahdieh 5, Varamin, Iran; P-Code: 3371786837; Tel: +98 292222 6954; Fax: +98 292222 4767; E-mail: hakimfaraji@yahoo.com
[19]. Zhao and Lee reported liquid-phase microextraction (LPME) for extraction of phenols [20].

Recently, a simple, quick and inexpensive LPME sample preparation method has been developed for extraction of analytes from water samples. This technique is based on distribution of the analytes between micro liters volume of the extraction solvent (floated on the surface of the aqueous sample) and the aqueous sample matrix [21].

The goal of this study was to assess the technique suitability for the detection of a group of the phenolic compounds in water samples. The analytes were monitored by liquid chromatography combined with diode array detector. The influence of different experimental parameters on the yield of the sample preparation step is described and discussed. In the end, this recommended method was employed to investigate the levels of the target species in several water samples.

\section{EXPERIMENTAL}

\subsection{Reagents}

The phenolic compounds include phenol (PN), 3chlorophenol (3CP), 2,4-dimethylphenol (24DMP), 2,4dichlorophenol (24DCP), 2,4,6-trichlorophenol (246TCP), 2,3,4,6-tetrachlorophenol (2346TeCP) and pentachlorophenol (PCP) were obtained from Merck (Darmstadt, Germany). Standard solutions $\left(2000 \mathrm{mg} \mathrm{L}^{-1}\right)$ from each individual compounds were prepared in methanol. The organic solvents (HPLC-grade or suprasolv for chromatography), sodium chloride and potassium chloride (analytical reagent grade) were purchased from Merck (Darmstadt, Germany) and Fluka (Buchs, Switzerland). Ultrapure water was prepared by a Milli-Q system (Bedford, MA, USA). Individual stock 
standard solution of $1000 \mathrm{mg} \mathrm{L}^{-1}$ for each compound was prepared in methanol and stored at $-20{ }^{\circ} \mathrm{C}$. Stock standard mixture of the phenolic compounds was weekly prepared by diluting the stock solutions with methanol. The working standard solutions were daily made by diluting the mixed stock solutions with Milli-Q water to the required concentration. A pH 2 buffer was prepared using $25 \mathrm{~mL}$ of $0.2 \mathrm{M} \mathrm{KCl}$ and $6.5 \mathrm{~mL}$ of $0.2 \mathrm{M} \mathrm{HCl}$ in $100 \mathrm{~mL}$ of water, and saturated salt solutions were prepared with $\mathrm{NaCl}$.

Tap water sample was freshly collected from our laboratory and mineral water was obtained from supermarket. The tap and mineral water samples were collected in glass bottles. The tap water sample was filtered before the analysis by a $0.45 \mu \mathrm{m}$ membrane filter (MSI, Westboro, MA, USA). The water samples were stored in refrigerator at $4{ }^{\circ} \mathrm{C}$ until their analysis.

\subsection{Apparatus}

The residual analysis was carried out using an Agilent 1100 HPLC equipped with a manual injector and diode array detector. A Zorbax Eclipse XDB-C18 column $(150 \mathrm{~mm} \times$ $4.6 \mathrm{~mm}, 5 \mu \mathrm{m}$ particle sizes) was used and all injections were performed manually with $20.0 \mu \mathrm{L}$ sample loop. The operating conditions were as follows: mobile phase, methanol/water, $95: 5 \mathrm{v} / \mathrm{v}$; flow rate, $0.8 \mathrm{~mL} / \mathrm{min}$; column temperature, $25 \pm 1{ }^{\circ} \mathrm{C}$; and the wavelength of detector, $220 \mathrm{~nm}$. Screw cap glass test tubes $(10 \mathrm{~mL})$ with conical bottoms (used as extraction vessels) were heated at $500{ }^{\circ} \mathrm{C}$ in a furnace (model CWF 1200, Carbolite, UK) to remove any organic compounds. Stirring the solution was carried out with a magnetic heater-stirrer (Heidolph MR 3001K, Germany). A simple water bath placed on the heater-stirrer was for controlling the temperature of the sample solutions.

\subsection{Extraction Procedure}

Extractions were carried out according to the following procedure: (1) a 20-mL aqueous solution containing the phenols was added into the sample vial with a $8 \mathrm{~mm} \times 4 \mathrm{~mm}$ magnetic stirring bar; (2) the sample vial was put on a MR $3001 \mathrm{~K}$ hot plate stirrer (Heidolph, Germany); (3) desired volume of the organic solvent was placed on the surface of the solution using a $25 \mu \mathrm{L}$ Hamilton syringe (Bondaduz, Switzerland); (4) the vial was sealed and the stirrer turned on; (5) after the extraction, sample vial was transferred into an ice beaker, and the organic solvent was solidified nearly 5 min afterwards; (6) the solidified organic solvent was transferred into the conical vial by a simple spatula where, it started to melt; (7) the whole melted solvent was injected into the HPLC for quantification.

\section{RESULTS AND DISCUSSION}

\subsection{Selection of Extraction Solvent}

The selection of a proper extraction solvent is of great importance for the optimization of the LPME process. To choose an appropriate organic solvent, the following points should be considered. Firstly, the chosen solvent should illustrate a high boiling point and a low vapor pressure in order to reduce the risk of evaporation [22]. Secondly, it should exhibit a good chromatographic behavior [23] and, thirdly, the partitioning coefficient of the analyte should be high. Furthermore, the solvent must have a good affinity for the target compounds [24] and, finally, it should demonstrate a melting point near the room temperature (in the range of $10-30{ }^{\circ} \mathrm{C}$ ) [21]. According to these considerations, several extracting solvents, including 1-undecanol, 1-dodecanol, 2dodecanol and $n$-hexadecane were considered. Among the tested extracting solvents, 1-undecanol presented the best extraction efficiency, while its chromatographic peak was easily separated from the analyte peaks. Also because of its low vapor pressure at the extraction conditions, the extract was stable at the extraction period (Fig. 1). Thus, 1undecanol was chosen as the extracting solvent in this investigation. It is noteworthy that a $20 \mathrm{~mL}$ aqueous solution spiked into with the phenols (at the concentration level of 5.0 $\mu \mathrm{g} \mathrm{L}^{-1}$ ) was used in the extraction studies.

\subsection{Volume of Extraction Solvent}

The effect of micro drop volume on the analytical signal was studied in the range of 10.0-20.0 $\mu \mathrm{L}$. Fig. (2) shows that there was a corresponding increase in the analytical signal of phenolic compounds from 10.0 until $20.0 \mu \mathrm{L}$ of solvent volumes. Based on LLE equations, rate of the analytes

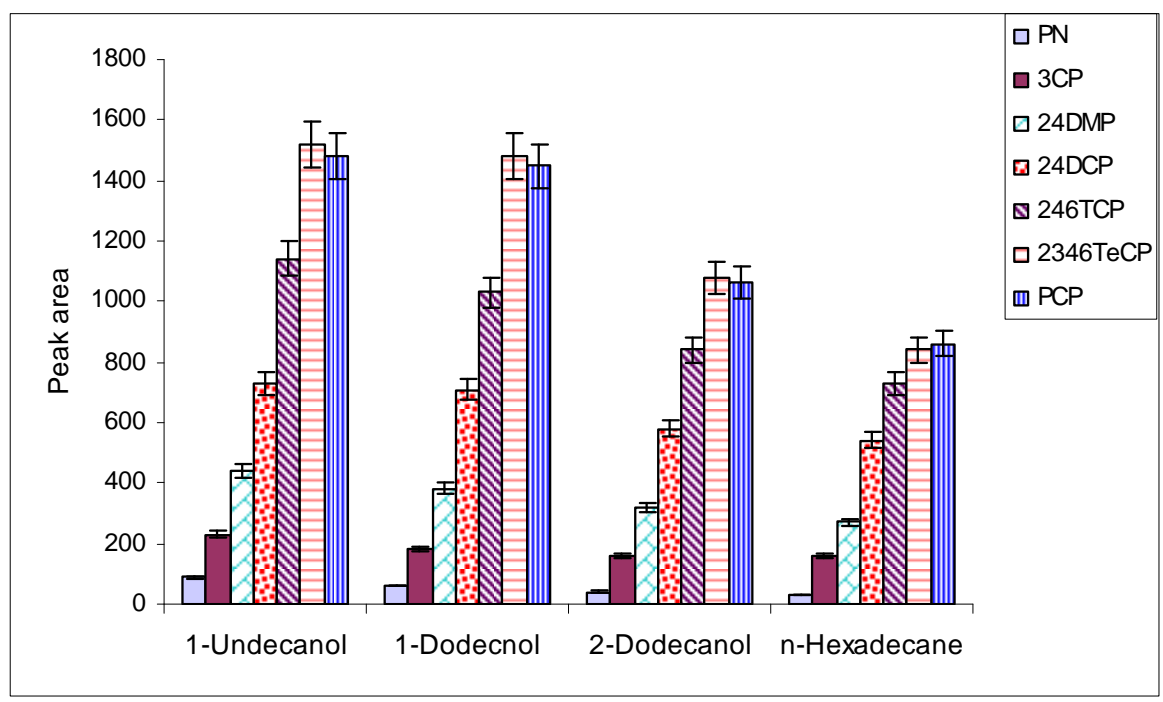

Fig. (1). Effect of organic solvent type on extraction efficiency. 
migration into micro drop is directly related to the surface area between the two liquid phases and is inversely related to the organic-phase volume. Thus, increase in the drop volume raises the interfacial area following the analytical signals. But further increase in the micro drop volume leads to decrease in the analytical signals. Hence, the volume of 14.0 $\mu \mathrm{L}$ was chosen as the optimal solvent volume.

\subsection{Stirring Rate}

Agitation of the sample solution enhances the rate of extraction. The stirring speed has a direct influence on extraction efficiency in limited times due to increasing mass transfer into the organic drop. In this work, the samples with a volume of $20 \mathrm{~mL}$ were stirred at different stirring speed $(400,600,800,1000$ and $1200 \mathrm{rpm})$ on a stirrer plate. Based on Fig. (3), $1200 \mathrm{rpm}$ was chosen as the suitable stirring speed.

\subsection{Effect of Ionic Strength and $\mathrm{pH}$}

The addition of acid and salt, singularly and in combination, was investigated as a means of enhancing the amount extracted by the solvent. Fig. (4) shows signal intensity ob- tained for all conditions using a $20 \mathrm{~min}$ extraction time, which was also used for control samples of the same concentration at neutral $\mathrm{pH}$ and with no salt added. The positive effects of both acid and salt can be realized when they are used in combination. Thus, according to the results, the positive effects of both acid and salt can be realized when they are used in combination. With $\mathrm{pH} 2$ and saturated salt conditions, the amount extracted for every analyte in the mixture was greater than the control sample at $\mathrm{pH} 7$ and with no salt added. Under these conditions, all phenolic compounds are in their neutral form and are salted out of solution and into the solvent.

\subsection{Sample Temperature}

The effect of sample temperature on extraction efficiency was also investigated between 26 and $55^{\circ} \mathrm{C}$. Generally, by increasing temperature, higher enrichment factors can be obtained in LPME experiments. This process facilitates mass transfer of the analytes from the sample into the organic solvent and thus increases the efficiency of the extraction. Results showed that by increasing the temperature, the extraction efficiency was increased (Fig. 5). At high temperatures

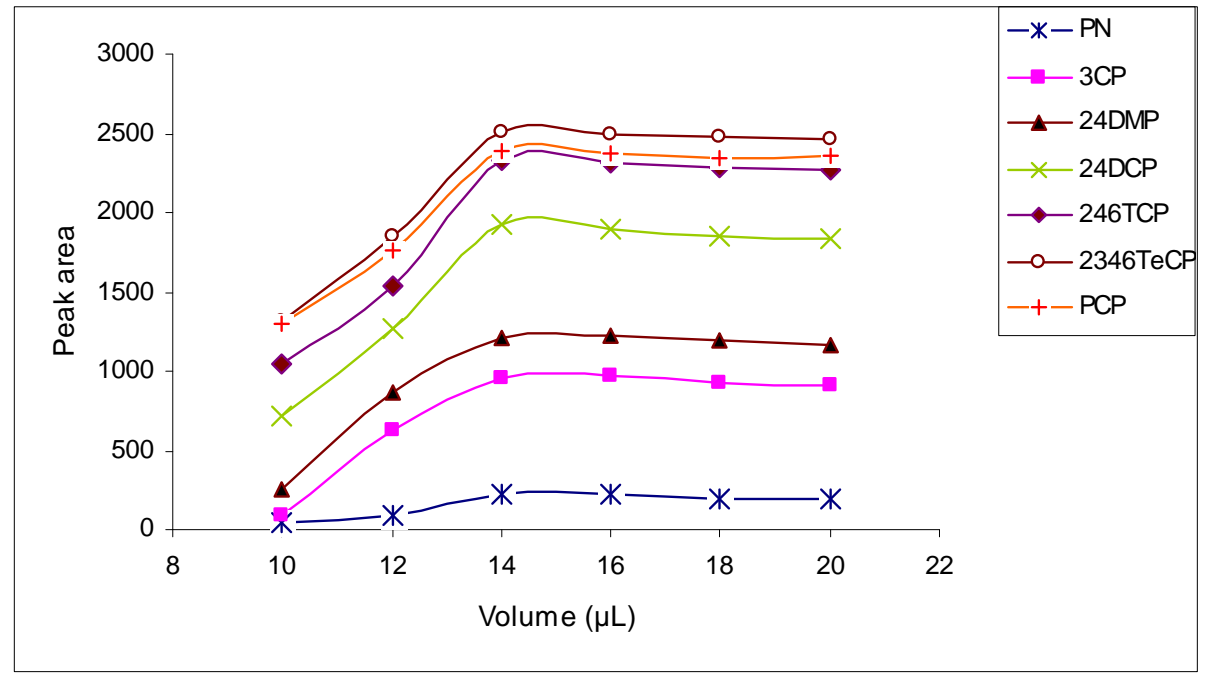

Fig. (2). Extraction efficiencies obtained for different organic solvent volume.

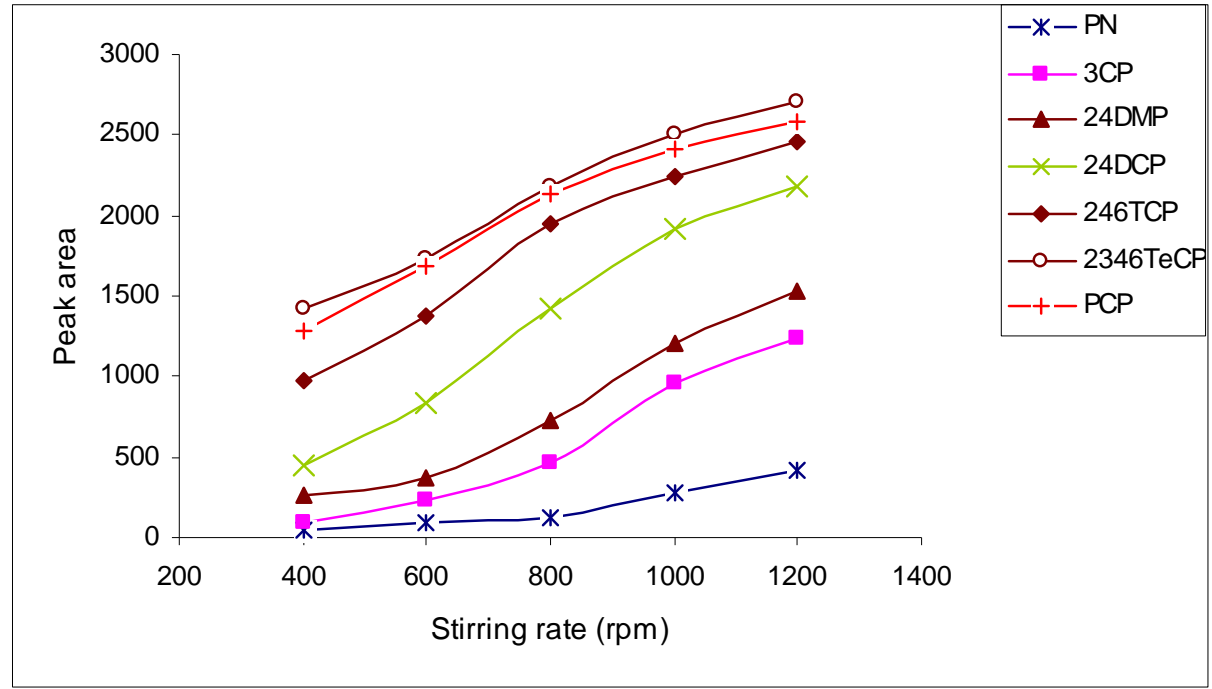

Fig. (3). Effect of stirring rate on the relative peak area. 


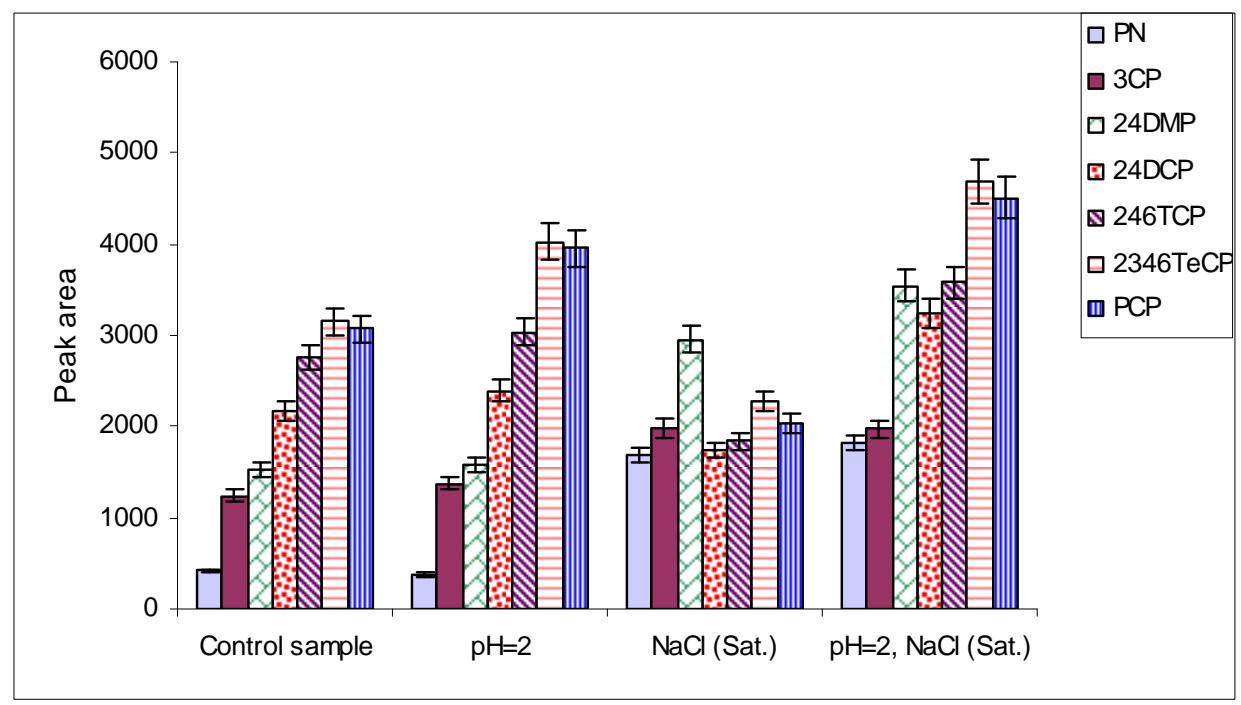

Fig. (4). Effect of acid and salt on extraction.

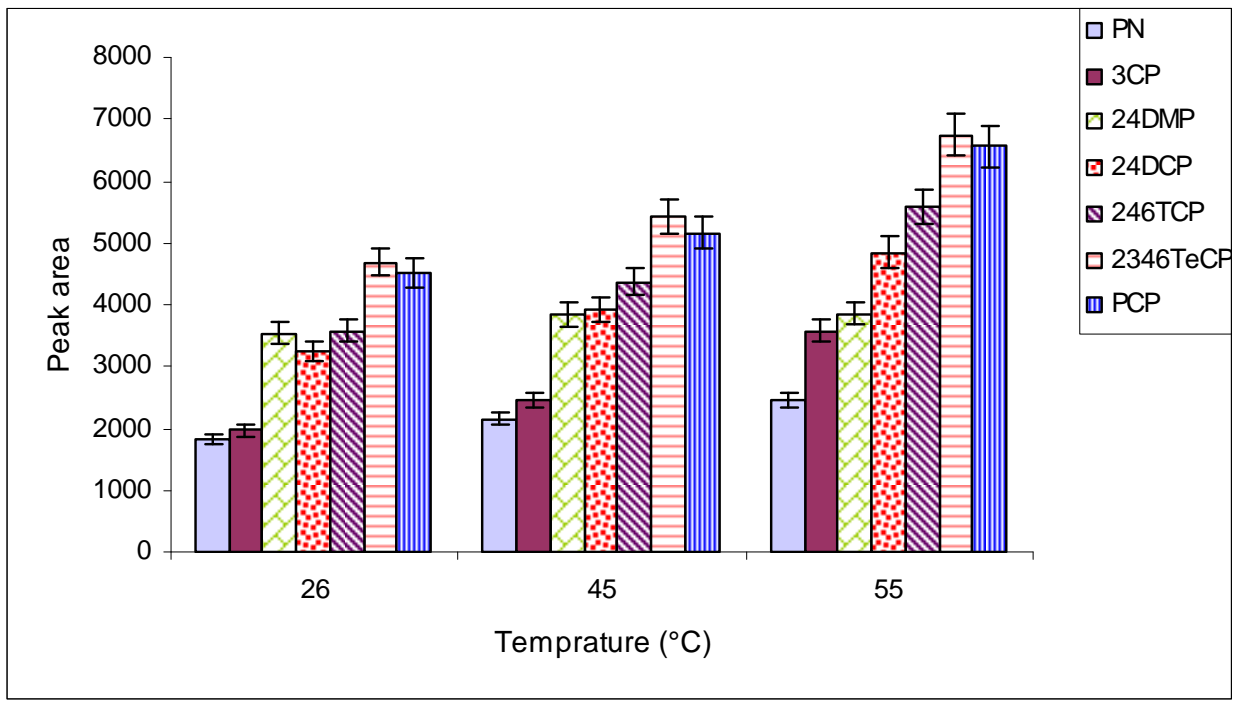

Fig. (5). Influence of temperature on the extraction efficiencies.

$\left(>55{ }^{\circ} \mathrm{C}\right)$, the over-pressurization of the sample vial made the extraction system unstable. Thus, in further experiments the sample vial temperature was held at $55^{\circ} \mathrm{C}$.

\subsection{Extraction Time}

To increase the precision and sensitivity of the LPME method, it is necessary to select an exposure time that guarantees the equilibrium between the aqueous and organic phases. Therefore, the extraction time plays a very essential role in the whole process. The range of extraction time investigated was 5-30 min with other extraction conditions being constant. Fig. (6) shows that there was a corresponding increase in analytical signal from 5 to $15 \mathrm{~min}$, followed by a period of stability. An extraction time of $15 \mathrm{~min}$ was selected as a reasonable compromise between enrichment factor and analysis time.

\subsection{Quantitative Evaluation and Real Samples}

Quantitative parameters of the purposed method, such as linearity ranges (LR) and limit of detections (LOD) were calculated by pre-concentration $20 \mathrm{~mL}$ of water sample, spiked by standard solution of phenolic compounds as summarized in Table 1. As it is illustrated, that the LR were obtained at concentration range of $0.3-870 \mu \mathrm{g} \mathrm{L}^{-1}$ for phenolic compounds, (RSD < 10.1\%). The coefficient of determinations $\left(r^{2}\right)$ was satisfactory in the range of 0.9973-0.9992 for all the analytes studied. Limit of detections, based on a signal to noise ratio of $\mathrm{S} / \mathrm{N}=3$ [25], were ranged from 0.05 to $3.0 \mu \mathrm{g} \mathrm{L}^{-1}$.

\subsection{Analysis of Real Sample}

In order to evaluate efficiency of the proposed method in monitoring of low levels of phenols, their levels in tap and mineral water were investigated. Results are summarized in Table 2. The chromatograms obtained by HPLC-DAD of unspiked mineral water and that spiked at two concentrations of each analyte after the developed method at optimum conditions is shown in Fig. (7).

\section{CONCLUSION}

A novel LPME and in situ derivatization method coupled with HPLC-DAD for pre-concentration and determination of 


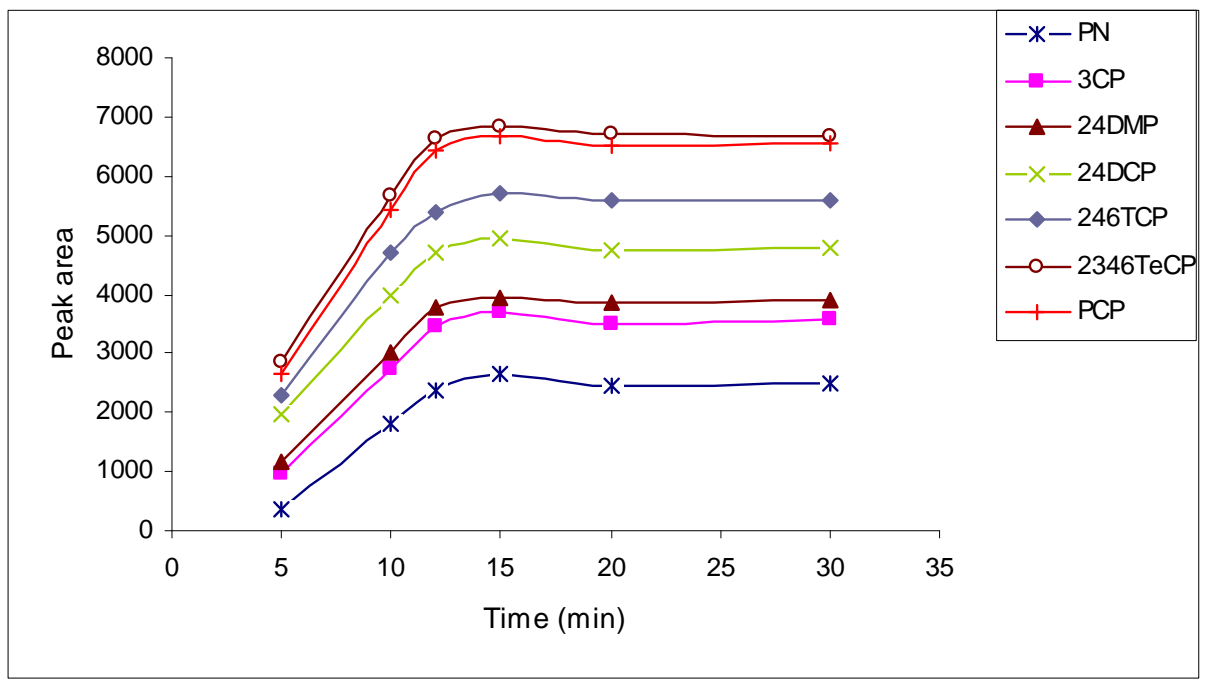

Fig. (6). Time profiles obtained for the studied analytes.

Table 1. Figures of Merit of the Proposed LPME-HPLC-DAD Method for Pre-Concentration and Determination of Phenols

\begin{tabular}{|c|c|c|c|c|}
\hline Analytes & $\mathbf{L O D}^{\mathrm{a}}\left(\boldsymbol{\mu g} \mathbf{L}^{-1}\right)$ & $\mathbf{L R}^{\mathrm{b}}(\boldsymbol{\mu g} \mathbf{L}-\mathbf{1})$ & $\mathbf{r}^{\mathbf{2}}$ & $\mathbf{R S D}^{\mathbf{c}} \mathbf{\%}(\mathbf{n}=\mathbf{5})$ \\
\hline \hline PN & 3.00 & $5.0-300$ & 0.9973 & 0.9984 \\
\hline $3 \mathrm{CP}$ & 2.00 & $3.0-300$ & 0.9975 & 5.4 \\
\hline $24 \mathrm{DMP}$ & 0.40 & $1.0-300$ & 0.9983 & 5.4 \\
\hline $24 \mathrm{DCP}$ & 0.20 & $1.0-200$ & 0.9992 & 6.1 \\
\hline $246 \mathrm{TCP}$ & 0.08 & $0.5-870$ & 0.9989 & 4.9 \\
\hline $2346 \mathrm{TeCP}$ & 0.06 & $0.3-870$ & 0.9987 & 7.2 \\
\hline PCP & 0.05 & $0.3-870$ & \\
\hline
\end{tabular}

${ }^{\mathrm{a}}$ Limit of detection.

${ }^{\mathrm{b}}$ Linearity range.

${ }^{\mathrm{c}}$ Relative standard deviation.

Table 2. The Results Obtained from Analysis of Real Water Samples

\begin{tabular}{|c|c|c|c|c|c|c|c|c|}
\hline \multirow[t]{2}{*}{ Analytes } & \multicolumn{4}{|c|}{ Recovery of Tap Water (\%) } & \multicolumn{4}{|c|}{ Recovery of Mineral Water (\%) } \\
\hline & $10.0\left(\mu g L^{-1}\right)$ & $\left(\right.$ RSD $\left.^{\mathrm{a}}\right)$ & $4.0\left(\mu g \mathrm{~L}^{-1}\right)$ & $\left(\right.$ RSD $\left.^{\mathrm{a}}\right)$ & $10.0\left(\mu g L^{-1}\right)$ & $\left(\mathbf{R S D}^{\mathrm{a}}\right)$ & $4.0\left(\mu \mathrm{g} \mathrm{L}^{-1}\right)$ & $\left(\mathrm{RSD}^{\mathrm{a}}\right)$ \\
\hline $\mathrm{PN}$ & 86.5 & $(6.5)$ & 87.2 & $(6.9)$ & 88.6 & $(6.9)$ & 87.0 & $(7.4)$ \\
\hline $3 \mathrm{CP}$ & 91.6 & $(5.1)$ & 90.8 & $(8.5)$ & 89.3 & $(5.5)$ & 94.3 & $(9.1)$ \\
\hline $24 \mathrm{DCP}$ & 95.7 & $(7.2)$ & 93.9 & $(6.8)$ & 84.6 & $(4.8)$ & 86.9 & $(8.1)$ \\
\hline $246 \mathrm{TCP}$ & 94.3 & $(8.4)$ & 93.6 & $(8.2)$ & 95.0 & $(6.1)$ & 86.3 & $(8.7)$ \\
\hline $2346 \mathrm{TeCP}$ & 101.0 & $(6.8)$ & 99.5 & $(7.4)$ & 102.4 & $(5.9)$ & 98.4 & $(8.4)$ \\
\hline PCP & 92.3 & $(4.5)$ & 91.1 & (4.9) & 94.7 & $(7.1)$ & 92.9 & $(10.3)$ \\
\hline
\end{tabular}

${ }^{a} \mathrm{n}=3$

seven phenolic compounds in water samples has been developed. The present method in comparison with other sample preparation methods is simple in operation, has good repeatability, lower analysis cost and relative high recoveries. In this technique sample preparation time as well as the consumption of toxic organic solvents has been minimized without affecting the sensitivity of technique. Different water samples showed no matrix influence in this method. 


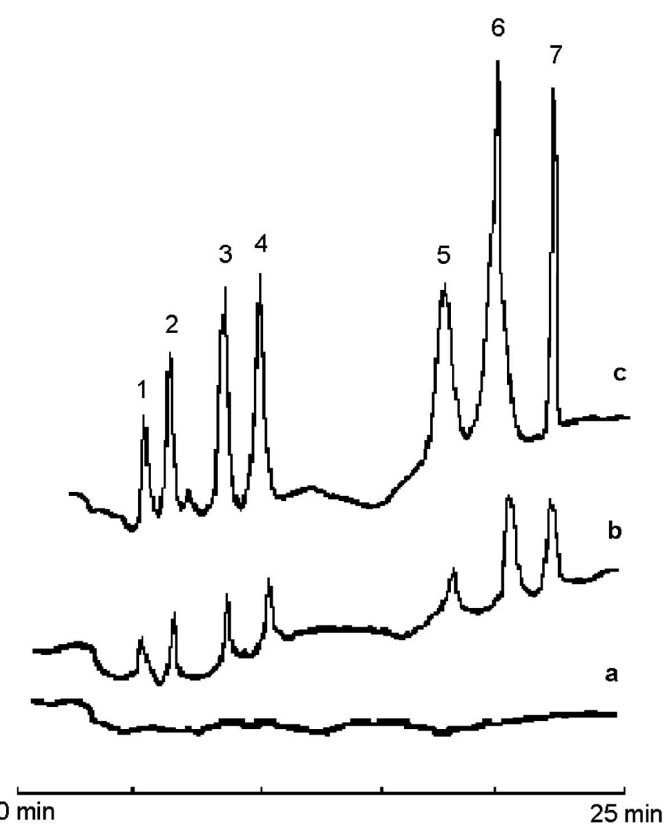

Fig. (7). Chromatograms of mineral water sample, (a) unspiked; (b) spiked at $4.0 \mu \mathrm{g} \mathrm{L}^{-1}$ and (c) spiked at $10.0 \mu \mathrm{g} \mathrm{L}^{-1}$ phenols. (1) PN, (2) 3CP, (3) 24DMP, (4) 24DCP, (5) 234TCP, (6) 2346TeCP, (7) PCP.

\section{ACKNOWLEDGEMENTS}

The authors gratefully acknowledge the financial support provided by the Research Council of the Islamic Azad University of Varamin to carryout this work.

\section{REFERENCES}

[1] Drinking Water Directive 80/778/EEC, Commission of the European Communities 1980.

[2] EEC Drinking Water Guideline 80/779/EECNOL 229/11-29, 1980.

[3] Chimuka, L.; Nefale, F.; Masevhe, A. Determination of phenols in water samples using a supported liquid membrane extraction probe and liquid chromatography with photodiode array detection. S. Afr. J. Chem., 2007, 13, 102-108.

[4] Puig, D.; Barceló, D. Off-line and on-line solid-phase extraction followed by liquid chromatography for the determination of priority phenols in natural waters. Chromatographia, 1995, 40, 435-444.

[5] Li, J.; Dong, X.; Jiang, Y.; Gao, Q.; Jiang, Z.; Cheung, Z.W.H.; Duan, R.; Dong, T.X.; Tu, T.; Tsim, K.W.K. Simultaneous determination of phenols in Radix Polygalae by high performance liquid chromatography: Quality assurance of herbs from different regions and seasons. J. Sep. Sci., 2007, 16, 2583-2589.

[6] Liu, Y.; Wen, B.; Shan, X.Q. Determination of pentachlorophenol in wastewater irrigated soils and incubated earthworms. Talanta, 2006, 69, 1254-1259.

[7] Awawdeh, A.M.; Harmon, H.J. Spectrophotometric detection of pentachlorophenol (PCP) in water using water soluble porphyrins. Sens. Actuators B Chem., 2005, 106, 234-242.

[8] Codognoto, L.; Zuin, V.G.; de Souza, D.; Yariwake, J.H.; Machado, S.A.S.; Avaca, L.A. Electroanalytical and chroma- tographic determination of pentachlorophenol and related molecules in a contaminated soil: a real case example. Microchem. J., 2004, 77, 177-184.

[9] Fattahi, N.; Assadi, Y.; Millani Hosseini, M.R.; Zeini Jahromi, E. Determination of chlorophenols in water samples using simultaneous dispersive liquid-liquid microextraction and derivatization followed by gas chromatography-electron-capture detection. $J$. Chromatogr. A, 2007, 1157, 23-29.

[10] Bagheri, H.; Saraji, M. Conductive polymers as new media for solid-phase extraction: Isolation of chlorophenols from water sample. J. Chromatogr. A, 2003, 986, 111-119.

[11] EPA Method 8041, Phenols by Gas Chromatography: Capillary column technique, Environmental Protection Agency, Washington, DC, 1995, p. 1

[12] Ahn, Y.G.; Shin, J.H.; Kim, H.Y.; Khim, J.; Lee, M.K.; Hong, J. Application of solid-phase extraction coupled with freezing-lipid filtration clean-up for the determination of endocrine-disrupting phenols in fish. Anal. Chem. Acta, 2007, 603, 67-75.

[13] Faraji, H. $\beta$-Cyclodextrin-bonded silica particles as the solid-phase extraction medium for the determination of phenol compounds in water samples followed by gas chromatography with flame ionization and mass spectrometry detection. J. Chromatogr. A, 2005 , 1087, 283-288.

[14] Mousavi, M.; Noroozian, E.; Jalali Heravi, M.; Mollahosseini, A. Optimization of solid-phase microextraction of volatile phenols in water by a polyaniline-coated Pt-fiber using experimental design. Anal. Chim. Acta, 2007, 581, 71-77.

[15] Liu, H.; Li, J.; Liu, X.; Jiang, S. A novel multiwalled carbon nanotubes bonded fused-silica fiber for solid phase microextraction-gas chromatographic analysis of phenols in water samples. Talanta, 2009, 78, 929-935.

[16] Bagheri, H.; Babanezhad, E.; Khalilian, F. A novel sol-gel-based amino-functionalized fiber for headspace solid-phase microextraction of phenol and chlorophenols from environmental samples. Anal. Chim. Acta, 2008, 616, 49-55.

[17] Huang, X.; Qiu, N.; Yuan, D. Development and validation of stir bar sorptive extraction of polar phenols in water followed by HPLC separation in poly(vinylpyrrolididone-divinylbenzene) monolith . $J$. Sep. Sci., 2009, 32, 1407-1414.

[18] Huang, X.; Qiu, N.; Yuan, D. Direct enrichment of phenols in lake and sea water by stir bar sorptive extraction based on poly (vinylpyridine-ethylene dimethacrylate) monolithic material and liquid chromatographic analysis. J. Chromatogr. A, 2008, 1194, 134-138.

[19] Jeannot, M.A.; Cantwell, F.F. Solvent microextraction into a single drop. Anal. Chem., 1996, 68, 2236-2240.

[20] Zhao, L.; Lee, H.K. Determination of phenols in water using liquid phase microextraction with back extraction combined with highperformance liquid chromatography. J. Chromatogr. A, 2001, 931, 95-105.

[21] Khalili Zanjani, M.R.; Yamini, Y.; Shariati, S.; Jonsson, J.A. A new liquid-phase microextraction method based on solidification of floating organic drop. Anal. Chim. Acta, 2007, 585, 286-293.

[22] Tankeviciute, A.; Kazlauskas, R.; Vickackaite, V. Headspace extraction of alchole into a single drop. Analyst, 2001, 126, 1674 1677.

[23] Ebrahimzadeh, H.; Yamini, Y.; Kamarei, F.; Khalili-Zanjani, M.R Application of headspace solvent microextraction to the analysis of mononitrotoluenes in waste water samples. Talanta, 2007, 72, 193198.

[24] Tor, A.; Aydin, M.E. Application of liquid-phase microextraction to the analysis of trihalomethanes in water. Anal. Chim. Acta, 2006, 575, 138-143.

[25] Ingle, J.D.; Crouch, S.R. Spectrochemical Analysis, Prentice-Hall International, Inc. 1988, pp. 172-176. 